\title{
Política e afeto na produção de identidades e instituições: a experiência potiguar
}

\author{
Arnon A. M. de Andrade \\ Universidade Federal do Rio do Norte, Departamento de Educação
}

Convidado para dar um depoimento sobre os 40 anos da pós-graduação em educação no Brasil, não podia recusar a oportunidade de recuperar algumas lembranças importantes sobre o Programa de PósGraduação em Educação da Federal do Rio Grande do Norte (UFRN), sua origem, suas dificuldades, sua expansão e seu papel atual de apoio estratégico e solidariedade fraterna aos programas das regiões Norte e Nordeste do Brasil. Caras lembranças, também para mim, pois foi nesse contexto que vim para Natal, com minha família e onde tenho vivido muitos momentos de grande intensidade afetiva.

Tenho, entretanto, a nítida compreensão de que todas as minhas percepções são a partir de um lugar e, por mais privilegiado que tenha sido essa minha localização, em nenhum momento deixou de ser uma visão solidária com minhas conviç̧ões e meus sentimentos, enfim com a minha história. Também emito aqui opiniões que, por mais informadas que tenham sido e por mais que sejam resultantes de reflexões, são adesões também unilaterais. Minha intenção, ao fazer esse depoimento, foi enriquecer a discussão sobre os caminhos que tomamos e sobre os caminhos que devemos tomar.
O Rio Grande do Norte sempre teve uma vocação para a ação inovadora, e em conseqüência, se torna o local do experimento educacional do Projeto Satélite Avançado de Comunicações Interdisciplinares (SACI), um projeto desenvolvido pelo Instituto Nacional de Pesquisas Espaciais (INPE), ligado à Presidência da República, com o objetivo de oferecer, ao governo federal, subsídios para a implantação de um sistema de teleducação, (como era chamada a educação a distância naquela época) nos fins dos anos de 1960 e início da década de 1970.

Foi no Rio Grande do Norte que a escravidão foi abolida primeiro e onde a mulher votou e foi votada pela primeira vez; foi o Rio Grande do Norte o cenário para a primeira experiência do sistema de alfabetização Paulo Freire as conhecidas 40 horas de Angicos; na UFRN surgiu o Centro Regional de Treinamento e Ação Comunitária (CRUTAC); também no Rio Grande do Norte nasceu o Movimento de Educação de Base (MEB), que, com suas escolas radiofônicas, fez o melhor uso do rádio em educação que se tem notícia e que rapidamente se espalhou pelo Norte, Nordeste e Centro-Oeste do Brasil; e foi ainda no Rio Grande do Norte que aconteceu o projeto De pé no 
chão também se aprende a ler, uma marca importante na história da educação desse país. Não era, portanto, estranho que o SACI, uma ousadia tecnológica, tivesse lugar no Rio Grande do Norte.

Voltando ao início da conversa, o INPE elegeu o Rio Grande do Norte como local da experiência por diversas razões: porque já tinha um escritório em Natal, por conta das atividades desenvolvidas com a base de lançamentos de foguetes da Barreira do Inferno; porque a UFRN já era concessionária de um canal de televisão educativa; a Secretaria Estadual de Educação demonstrou interesse e, finalmente, mas não por último, no Rio Grande do Norte, as condições eram tão difíceis que os resultados bem poderiam ser projetados para as regiões mais pobres do país.

O Projeto SACI, idealizado pelo doutor Fernando Mendonça, diretor geral do INPE, pretendia experimentar o uso de satélites em educação, transmitindo programas de rádio e televisão para escolas de $1^{\circ}$ grau, escolhidas aleatoriamente entre todas as escolas municipais e estaduais do Rio Grande do Norte.

O projeto usaria algumas escolas para a recepção via satélite, com antenas parabólicas, e as outras utilizariam as emissoras rurais da Igreja católica, veiculadoras das aulas radiofônicas do MEB, ou a TVUniversitária de Natal, cujo canal pertencia à UFRN, embora ainda não instalada, e que o INPE implantaria em função da experiência. O Instituto Nacional de Estudos Pedagógicos (INEP) seria responsável pelos aspectos da pesquisa e a Fundação Centro Brasileiro de Televisão Educativa (FCBTVE) produziria os programas de rádio e televisão. O INPE, seguindo sua vocação, cuidaria da tecnologia utilizada para a geração e recepção de sinais e de desenvolvimento de soluções técnicas que facilitassem e barateassem o sistema.

Os parceiros do INPE não participaram da empreitada e o doutor Fernando de Mendonça decidiu seguir sozinho com o projeto. O país não dispunha de recursos humanos qualificados em quantidade para tocar as diversas tarefas de produção e o INPE contratou uma instituição especializada em televisão educativa da Inglaterra, convidou comunicadores e educadores de várias universidades brasileiras e começou a formar quadros para a produção de programas de televisão. Em janeiro de 1971 começava o curso de especialização do qual sairiam muitos dos produtores de materiais pedagógicos desse e de muitos outros projetos pelo país.

O curso de mestrado em tecnologia educacional iniciado em 1973 foi a conseqüência da seriedade com que o INPE tocou o projeto, da falta de experiências comparáveis, no Brasil ou no exterior, do ambiente de produção científica que caracterizava o trabalho e da necessidade de qualificar em alto nível os pesquisadores do projeto. Planejamento, meios e avaliação eram as três áreas de concentração do mestrado, que trazia um conceito preciso de tecnologia educacional - uma nova área de investigação e desenvolvimento, fundada nos avanços da tecnologia da comunicação, nas teorias da comunicação e da aprendizagem e na engenharia de sistemas, uma das áreas em que o INPE já era pioneiro.

Vivíamos um dos piores momentos políticos de toda a história do Brasil e as universidades brasileiras, atingidas profundamente em sua autonomia, resistiam, silenciadas, às imposições do governo central. O INPE, um órgão ligado à Presidência da República e de interesse dos setores de segurança do governo militar, era visto com suspeita pelas universidades. Mas, ao mesmo tempo, já era considerado um centro de excelência em pós-graduação e a implantação do mestrado em educação provocava um duplo sentimento de receio e de respeito.

Nas três vezes em que o mestrado abriu vagas e selecionou alunos, muitos foram os candidatos, vindos de muitos estados da federação. $\mathrm{O}$ fato de ter o SACI como possível área de desenvolvimento dava ao programa um caráter de treinamento em serviço e isso era diferente do programa brasileiro de pós-graduação que começava a disseminar os mestrados pelo país. O mestrado era de tal forma ligado à prática do Projeto SACI que não podiam ser separados e as dissertações, como os artigos publicados e apresentados em congressos, eram publicações do projeto.

Em 1975, as pressões, dentro do próprio governo federal, para interromper a experiência do INPE 
eram enormes e, embora os objetivos e metas do SACI ainda não tivessem sido alcançados, o projeto foi interrompido. Como não se podia jogar para o alto tudo o que tinha sido construído, um plano de sobrevivência começou a ocupar as mentes de pesquisadores, professores e alunos do mestrado e do Projeto SACI.

Em meados de 1975 o Ministério da Educação (MEC), por intermédio do Programa Nacional de Teleducação (PRONTEL), financiou o treinamento de funcionários da UFRN e da Secretaria de Educação que trabalhariam na TV-Universitária e no Sistema de Teleducação do Rio Grande do Norte (SITERN). A UFRN e a Secretaria Estadual de Educação e Cultura (SEEC) receberiam os equipamentos que tinham sido usados na produção e transmissão dos programas de rádio e televisão e os receptores instalados nas quatrocentas escolas do projeto. Esse processo foi chamado de estadualização do Projeto SACI.

Quanto ao mestrado em tecnologia educacional, a primeira alternativa, já que a maioria dos alunos era da região, foi transferi-lo para a Universidade Federal de São Carlos (UFSCar), que estava criando seu programa de pós-graduação em educação. Reuniões e visitas aconteceram na esperança de que houvesse um transplante do estrado em Tecnologia Educacional do INPE para a UFSCar. Isso não aconteceu e o reitor da UFRN, prof $^{\circ}$ Domingos Gomes de Lima, achou que seria uma boa oportunidade para conseguir apoio e recursos do MEC e do próprio INPE e para começar a pós-graduação stricto sensu no Rio Grande do Norte.

Os mestres do INPE de São José dos Campos foram transferidos para a UFRN (ambos eram órgãos federais) e mobilizados pela reitoria, juntamente com professores do Departamento de Educação, para a elaboração de um projeto de mestrado em tecnologia educacional, que pudesse ser visto como uma continuação do mestrado em tecnologia educacional do INPE e que justificasse, politicamente, a reivindicação de apoio adicional do MEC.

O Departamento de Educação não foi simpático à idéia de fazer um mestrado em tecnologia educacional com as áreas de concentração em planejamen- to, meios e avaliação. O mestrado foi iniciado em 1978 em educação com uma área de concentração em tecnologia educacional, até que se implementasse uma outra área, na qual o departamento já tinha pessoal qualificado e que já vinha oferecendo cursos lato sensu: educação do pré-escolar. Foi essa, no ano seguinte, a segunda área de concentração do mestrado da UFRN. O corpo docente do curso era pequeno, tínhamos apenas três doutores - dois americanos, que ficaram no Brasil por pouco tempo, e a professora Neide Varela, que havia obtido seu doutorado em educação do pré-escolar na Universidade de São Paulo (USP) e que se tornou, logo que chegou, a primeira coordenadora do mestrado.

O curso surgiu em um modelo conservador, com muitas disciplinas, sem laboratório e com exageradas expectativas em relação às dissertações - que, como acontecia no resto do país, terminava por prolongar a permanência dos alunos no curso quase indefinidamente e por ampliar a evasão. O Sistema de Teleducação e a TV-Universitária, embora utilizados em uma ou outra disciplina, não se constituíram no laboratório da pós-graduação, como o SACI tinha sido no INPE.

O ano de 1979 foi de qualificação. De todos os departamentos acadêmicos, saíram professores para cursos de doutorado, no Brasil e no exterior. A UFRN, a exemplo do que acontecia na Universidade Federal da Paraíba (UFPB), aproveitando o apoio da Coordenação de Aperfeiçoamento de Nível Superior (CAPES), não somente contratou professores qualificados como estimulou a qualificação de seus quadros no exterior. Foi o primeiro ano do convênio com o Comitê Francês de Avaliação da Cooperação Universitária com o Brasil (CAPES/COFECUB), para o desenvolvimento de pesquisas e a qualificação de brasileiros em nível de doutorado em universidades francesas. O Nordeste do Brasil, particularmente Paraíba e Rio Grande do Norte, aproveitou a oportunidade e enviou um bom número de professores para fazer o doutorado em universidades francesas. Nos anos que se seguiram, muitos outros trilharam o mesmo caminho.

Em 1983 começamos a rever nosso curso e a 
planejar um seminário de reformulação do mestrado em educação. Estávamos vivendo a redemocratização, a anistia já tinha sido aprovada e havia uma explosão editorial como nunca tinha havido no país. Realizamos um seminário nacional para comemorar os 20 anos da experiência de Angicos, com a presença do próprio Paulo Freire. Uma das conseqüências desse sentimento de liberdade foi a abertura de mais uma área de concentração: política, estado e educação. Tínhamos, já, mais de uma dezena de doutores e pensávamos um doutorado na forma de consórcio com os outros mestrados em educação do Nordeste.

Os programas das universidades federais da Bahia, de Pernambuco, Rio Grande do Norte, Ceará e Sergipe discutiram um modelo interinstitucional e isso cristalizou o sentimento de que, qualquer que fosse a solução, os doutorados deveriam ter um olhar privilegiado para o Nordeste. Não apenas como espaço de pesquisa, mas como ambiente de parceria e colaboração, e esse sentimento é uma das marcas da nossa pós-graduação. Aliás, o Rio Grande do Norte tem entre suas peculiaridades um traço cosmopolita que o diferencia na região. ${ }^{1}$

O projeto regional não vingou. A Universidade Federal da Bahia (UFBA) foi a primeira a criar seu doutorado e, talvez pela distância, talvez pela diferença de foco ou pela fragilidade de um programa novo, não se tornou o doutorado do Nordeste de que carecíamos. A essa altura, nosso mestrado abandonava o modelo das áreas de concentração e começava a experimentar uma estrutura mais flexível, mais representativa do perfil do corpo docente e das demandas da sociedade. Começávamos a organização, em gru-

${ }^{1}$ Durante a II Guerra Mundial, Natal tinha aproximadamente cinqüenta mil (50.000) habitantes e recebeu cerca de dez mil (10.000) soldados americanos. O impacto cultural já foi objeto de muitos textos. A cidade, após alguns séculos de estagnação, voltou a crescer a partir da década de 1960 e, mais rapidamente, a partir da década de 1970. Hoje a população de Natal é constituída na sua maioria por pessoas do interior ou de outros estados da região ou seus descendentes. pos de pesquisa (os núcleos), que daria sustentação a um doutorado mais aberto. O mestrado em educação também começava a experimentar o intercâmbio, recebendo alunos de outros estados e fazendo um convênio com a Universidade do Estado (UERN), sediada em Mossoró.

Em 1993, fizemos a agenda para a criação do nosso doutorado. Um doutorado em educação teria, a nosso ver, que ser marcado mais pelo caráter de treinamento em pesquisa, do que de curso com extensa grade curricular e exagerado conteudismo. Os alunos deveriam apresentar um projeto viável, dentro de uma das áreas em que os grupos estivessem trabalhando, o que certamente daria mais qualidade à orientação; o currículo deveria abrir a possibilidade de oferta de disciplinas organizadas em função dos trabalhos em desenvolvimento. Deveria ser possível fazer o doutorado sem ter feito o mestrado ou de fazer o doutorado a partir de um exame de mudança de nível no final do mestrado; era desejável que a produção das teses fosse firmemente influenciada pela convivência nos grupos de pesquisa e perdesse o caráter de produção solitária - a participação dos alunos (graduação, mestrado e doutorado), nos trabalhos do grupo de pesquisa, deveria ser indispensável.

Começamos a trabalhar na concepção do projeto e percebíamos que em todos os lugares os mesmos sentimentos e as mesmas expectativas alimentavam o debate e direcionavam as mudanças, lentas é verdade, mas constantes e disseminadas. Nos Encontros de Pesquisa do Nordeste (EPEN), ${ }^{2}$ nas reuniões anuais da ANPEd, nas discussões promovidas pela própria CAPES, todas as nossas preocupações estavam presentes. Resolvemos levar particularmente a discussão do nosso doutorado para fora da UFRN e em 1991 apresentamos a nossa proposta, ainda em discussão, no EPEN de Fortaleza - ali, algumas vozes mostraram o temor de que os doutorados do Nordes-

${ }^{2}$ A inclusão dos programas do Norte nos Encontros Regionais de Pesquisa de Educação só ocorreu a partir da decisão tomada no EPEN de 1999, realizado em Salvador. 
te produzissem uma endogenia perniciosa. Naquela ocasião, só a UFBA tinha o seu doutorado; a UFRN e a Universidade Federal do Ceará (UFC) organizaram seus doutorados simultaneamente.

Conseguimos espaço na Reunião da Sociedade Brasileira de para o Progresso da Ciência (SBPC) de Pernambuco em 1993 e levamos nossa proposta para apresentação e discussão. Um doutorado com poucos créditos, com uma grade mutante, com a obrigatoriedade de convivência diária, com a coletivização da produção e individualização de responsabilidades, articulado com o mestrado e com a especialização (essa era nossa intenção na época), com a participação dos alunos nas pesquisas da base, ${ }^{3}$ e interação de professores e alunos de diversos níveis, inclusive da graduação... Felipe Serpa, professor do programa de pós-graduação da UFBA, estava presente e disse de sua admiração e adesão à proposta, mas alertava-nos para uma coisa que poderia nos derrubar: o cotidiano.

Organizamos um seminário para discutir e arejar a discussão sobre a proposta. Convidamos, como palestrante, o professor Osmar Fávero, que realizava uma pesquisa, encomendada pelo Conselho Nacional de Desenvolvimento Científico e Tecnológico (CNPq), sobre as tendências da pós-graduação em educação no Brasil. O seminário confirmou nossas percepções. Nossa proposta era avançada, mas estava no caminho que a pós-graduação da área viria a percorrer. Antes mesmo que tivéssemos problemas com o cotidiano do funcionamento de um curso com uma concepção diferente, e ainda os temos bastante, começamos a ter problemas com a presunção e a arrogância de muitos de nossos pares dentro e fora da UFRN.

Em 1995, recebemos o professor Jacques Therrien e a professora Bernardete Gatti, enviados pela CAPES para a verificação in loco das condições de ofer-

${ }^{3}$ Base de pesquisa - foi assim que a UFRN institucionalizou os grupos de estudos e pesquisas; as bases têm constituição e funcionamento regulamentado pelo Conselho de Ensino Pesquisa e Extensão (CONSEPE) e concorre a bolsas e recursos financeiros oferecidos por agências de fomento e pela própria universidade. ta, das expectativas do corpo docente, da coerência da proposta e nossas possibilidades. O Conselho Técnico Científico (CTC) da CAPES acatou o parecer da comissão de verificação e recomendou o credenciamento do programa. Havia uma ingênua sensação de dever cumprido. Mal sabíamos que nada havia terminado. Ali é que começaria o cotidiano de que falara Felipe Serpa. Não se muda por decreto concepções que serviram de balizamento de toda uma vida acadêmica. Não era fácil abordar os problemas de modo transdisciplinar, não era fácil a orientação aberta e coletiva, não era fácil a convivência diária de professores e alunos, acostumados todos ao relacionamento modular de aulas e encontros agendados... Nosso programa recebeu a adesão do corpo docente, consciente de que toda uma cultura teria de ser mudada. Mas nossos maiores adversários não eram internos. Na avaliação de 1998, menos de três anos após à instalação do programa, depois do parecer favorável da comissão de verificação e de ter sido recomendado pelo CTC, ainda sem dados suficientes para avaliar nosso programa a comissão de avaliação, composta por nossos pares, nos desqualificou. Mantendo nossa tradição, inovamos, resistimos, superamos e fizemos história. Enfrentar as dificuldades, e superá-las coletivamente, é sempre uma experiência agregadora e gratificante e isso nos dá um tom alegre e esse espírito de corpo que nos caracteriza.

Embora nosso programa tenha origem no mestrado do INPE, ainda mantenha a unidade entre a teoria e a prática e tenha, entre suas linhas de pesquisas, os temas das antigas áreas de concentração, hoje somos muito diferentes, até porque são outros o nosso tempo e o nosso espaço.

Hoje temos um dos programas de maior visibilidade do país. Na última seleção, tivemos candidatos de dezoito estados da federação; mantemos programas de qualificação institucional com sete instituições do Norte e Nordeste do Brasil. Somos o maior e o mais bem avaliado programa da UFRN. O cotidiano continua sendo nossa principal preocupação - sabemos, de toda essa experiência, que a construção é lenta e silenciosa, mas a destruição pode ser rápida e rui- 
dosa. Temos perdido professores fundadores e nosso espaço e nossas condições materiais têm-se tornado terrivelmente limitantes, mas há em cada um de nós uma determinação de continuar melhorando. De uma coisa estamos certos: política e afeto são indispensáveis para a construção das pessoas e das instituições.

ARNONALBERTO MASCARENHAS DE ANDRADE, doutor pela Universidade de Caen - França, é professor do Programa de Pós-Graduação em Educação da Universidade Federal do Rio Grande do Norte (UFRN). Fez especialização em produção de TV educativa no Instituto Nacional de Pesquisas Espaciais (INPE) em 1971; fez o mestrado em tecnologia educacional, com área de concentração em meios (impressos, rádio e televisão) também no INPE em 1975. E-mail: arnon_andrade@uol.com.br

Recebido em maio de 2005

Aprovado em junho de 2005 


\section{Resumos/Abstracts}

Arnon A. M. de Andrade

Política e afeto na produção de identidades e instituições: a experiência potiguar

Recupera o histórico do mestrado em tecnologia educacional, iniciado em 1973, no Instituto de Pesquisas Espaciais, em São José dos Campos, estado de São Paulo, objetivando preparar pessoal qualificado para o Projeto Sistema Avançado em Comunicações Educativas (SACI). Resume esse projeto, que visava ao uso de satélites para transmissão de programas de rádio e televisão para escolas do ensino fundamental, e justifica a escolha do Rio Grande do Norte como área de experimentação. Informa que, após encerramento das atividades do Projeto SACI, cogitou-se transferir o mestrado em tecnologia educacional para a Universidade Federal do Rio Grande do Norte

(UFRN); no entanto, foi assumido apenas como a primeira área do mestrado em educação. Explica a criação do doutorado em educação na UFRN e as dificuldades de implantação do programa de pós-graduação, atualmente com forte expressão no Norte e Nordeste do país. Palavras-chave: tecnologia educacional; Projeto SACI; programa de pósgraduação em educação na UFRN

Politics and its affect on the production of identities and institutions: the experience of the
State of Rio Grande do Norte

This article recuperates the history of the Master's Degree Course in Educational Technology, initiated in 1973, at the Institute of Space Research, in São José dos Campos in the State of São Paulo whose goal was to prepare qualified personnel for the SACI Project - Advanced System in Educational Communication. It presents a synthesis of the Project which was aimed at the use of satellites for the transmission of radio and television programmes for primary schools and also explains the choice of Rio Grande do Norte as the pilot experience. It relates how after the closure of the SACI Project activities, the possibility of transferring the Master's course in educational technology to the Federal University of Rio Grande do Norte (UFRN) was considered. However, this field was only incorporated as the first field of study for the Master's Course in Education. The article further explains the creation of the doctoral programme in education at UFRN and the difficulties faced in implanting the postgraduate programme, at present one of the strongest in the North and Northeast of the country.

Key-words: educational technology; SACI Project; postgraduate programme in education at UFRN 